\title{
Estrogen-ERa signaling and DNA hypomethylation co-regulate expression of stem cell protein PIWIL1 in ERa-positive endometrial cancer cells
}

Zheng Chen ${ }^{1,2,3}$, Hua-Jing Yang ${ }^{1,2,3}$, Qin Lin ${ }^{1,2,3}$, Min-Jiao Zhu ${ }^{1,2,3}$, Ying-Ying Yu ${ }^{1,2,3}$, Xiao-Ying He $\mathrm{e}^{1,2,3^{*}}$ and Xiao-Ping Wan $^{4 *}$

\begin{abstract}
Background: We previously identified PIWIL1 as an oncogene involved in endometrial carcinogenesis. However, the mechanism of Piwil1 mediated regulation of tumorigenesis remains poorly understood.

Methods: The expression levels of target genes in endometrial cancer cells were detected by quantitative reverse transcription-PCR (RT-qPCR) and western blotting. Up- or down-regulation of ERa or PIWIL1 was achieved by transient transfection with expressing plasmids or short hairpin RNA (shRNA). Dual-luciferase reporter assays and chromatin immunoprecipitation (ChIP) were used to demonstrate the ERa bound to the half estrogen response element (half-ERE) located in PIWIL1 promoter. The expression of PIWIL1 and ERa in endometrial carcinoma tissues were investigated using immunohistochemistry and RT-qPCR. The proliferation ability of cancer cells were evaluated by MTT. Methylation status of the PIWIL1 promoter was detected by bisulfite sequencing PCR (BSP).

Results: In the present study, we found that PIWIL1 mediated $E_{2}$-stimulated cancer cell proliferation. In ERa-positive endometrial cancer cells, we demonstrated that estrogen-ERa signaling significantly up-regulated the expression of PIWIL1, which was mediated by binding of the ERa onto the PIWIL1 promoter. Furthermore, we found that a halfERE in the PIWIL1 promoter was essential for ERa binding. The PIWIL1 promoter was hypomethylated in ERa-positive endometrial cancer cells. Treatment with 5-aza-deoxycytidine (5-aza-dC) could up-regulate PIWIL1 expression.

Conclusions: These findings uncover a novel molecular mechanism by which estrogen-ERa signaling and DNA hypomethylation co-regulate PIWIL1 expression. These findings provide novel insights into the hormonal regulation of PIWIL1 in endometrial cancer and the PIWIL1's role in estrogen-stimulated endometrial carcinogenesis.
\end{abstract}

Keywords: Endometrial carcinoma, PIWIL1, ERa, Cell Proliferation, DNA methylation

\footnotetext{
* Correspondence: hexiaoying06@gmail.com; wanxiaoping@tongji.edu.cn ${ }^{1}$ Department of Obstetrics and Gynecology, International Peace Maternity and Child Health Hospital, School of Medicine, Shanghai Jiao Tong University, No.910, Hengshan Road, Shanghai 200030, China

${ }^{4}$ Department of Obstetrics and Gynecology, Shanghai First Maternity and Infant Hospital, Tong Ji University School of Medicine, No. 536, Changle Road, Shanghai 200080, China

Full list of author information is available at the end of the article
}

(c) The Author(s). 2020 Open Access This article is licensed under a Creative Commons Attribution 4.0 International License, which permits use, sharing, adaptation, distribution and reproduction in any medium or format, as long as you give appropriate credit to the original author(s) and the source, provide a link to the Creative Commons licence, and indicate if changes were made. The images or other third party material in this article are included in the article's Creative Commons licence, unless indicated otherwise in a credit line to the material. If material is not included in the article's Creative Commons licence and your intended use is not permitted by statutory regulation or exceeds the permitted use, you will need to obtain permission directly from the copyright holder. To view a copy of this licence, visit http://creativecommons.org/licenses/by/4.0/. The Creative Commons Public Domain Dedication waiver (http://creativecommons.org/publicdomain/zero/1.0/) applies to the data made available in this article, unless otherwise stated in a credit line to the data. 


\section{Background}

Endometrial carcinoma could be broadly categorized into two major types, referred to as type I and type II $[1,2]$. Clinically, most endometrial cancers are type I endometrial carcinomas which are estrogen-dependent endometrioid adenocarcinomas. Estrogen exerts its biological activities by binding to estrogen receptors, mainly the ER $\alpha$, which regulate the expression of a variety of genes involved in the carcinogenesis and progression of endometrial carcinoma [3-6].

PIWIL1 belongs to the PIWI family. PIWI was first identified in Drosophila as an essential factor for the self-renewal of germline stem cells [7]. Evidences showed that PIWIL1 as an oncogene was overexpressed in several tumors including gastric cancer, lung cancer, breast cancer, hepatocellular carcinoma, soft-tissue sarcoma, adenocarcinoma of the pancreas and endometrial cancer [8-14]. Most of the studies have focused on the role of PIWIs in gonadal development [15-19]. Estrogen has been suggested to play an important role in gonadal development. Several studies found that estrogen could regulate the expression of the PIWI family $[20,21]$. In our previous study, we found that the expression of PIWIL1 was higher in ER $\alpha$-positive endometrial cancer cell lines and tissues [9]. These publications give clues about regulation of PIWIL1 by estrogen in endometrial cancer. However, the molecular basis underlying the association between estrogen and PIWIL1 is not fully understood and remains a challenging question.

DNA methylation changes are hallmarks of every cancer type and can be early events in tumorigenesis. DNA methylation alterations may result in gene expression changes, namely gene silencing due to DNA hypermethylation and gene activation due to DNA hypomethylation. The frequent occurrence of cancerlinked DNA hypermethylation and DNA hypomethylation is associated with carcinogenesis [22]. Previous study observed the existence of promoter CpG island hypermethylation-associated silencing of PIWIL1 in primary seminoma and non-seminoma testicular tumors [23]. Some studies also found that promoter DNA hypomethylation of PIWIL1 could contribute to its aberrant expression in lung adenocarcinoma [24, 25]. However, the relationship between DNA methylation status of PIWIL1 promoter and PIWIL1 expression in endometrial cancer is unknown.

Herein, we demonstrate a novel molecular mechanism by which estrogen-ER $\alpha$ signaling and DNA hypomethylation co-regulate PIWIL1 expression in endometrial cancer. These findings provide novel insights into the hormonal regulation of PIWIL1 in endometrial cancer and the PIWIL1's role in estrogen-stimulated endometrial carcinogenesis.

\section{Methods}

\section{Patients and samples}

The study was approved by the Human Investigation Ethics Committee of the authors' affiliated institution. The samples of endometrial carcinoma and normal endometrial tissues were obtained after written informed consent at our institution from 2017 to 2018. Thirty formalin-fixed, paraffin-embedded tissues (15 ER $\alpha$ positive endometrial carcinoma and $15 \mathrm{ER} \alpha$-negative endometrial carcinoma) were used for immunohistochemistry, and 30 fresh frozen samples were used for RT-qPCR analysis. The stages and histological grades of these tumors were established according to the criteria of the Federation International of Gynecology and Obstetrics (FIGO) surgical staging system (2009) [26]. None of the patients underwent hormone therapy, radiotherapy or chemotherapy prior to surgery.

\section{Reagents and antibodies}

$\mathrm{E}_{2}, 5$-aza-deoxycytidine (5-aza- $\mathrm{dC}$, the methyltransferase inhibitor), 3-(4,5-dimethylthiazol-2-yl)-2,5-diphenyltetrazolium (MTT) were purchased from Sigma (St. Louis, MO). ICI 182,780 (ER $\alpha$ specific antagonist) was purchased from Tocris (Ellisville, MO). Rabbit polyclonal to anti-PIWIL1 antibody (ab105393) and Rabbit monoclonal to anti-ER $\alpha$ antibody (ab32063) were purchased from Abcam. GAPDH (\#5174, CST) was used as an internal control.

\section{Immunohistochemistry, RNA extraction, RT-qPCR and western blotting}

Immunohistochemistry, RNA extraction, RT-qPCR and western blotting were performed as described previously $[9,27]$. Primers sequences for RT-qPCR were shown in Additional file 1: Table S1. Evaluation of PIWIL1 and ER $\alpha$ staining was performed according to semi quantitative immunoreactivity scores [9].

\section{Cell preparation and culture conditions}

The human endometrial carcinoma cell lines, Ishikawa, RL95-2 (ER $\alpha$-positive) and HEC-1B (ER $\alpha$-negative) [28] were purchased from the Chinese Academy of Sciences Committee Type Culture Collection (Shanghai, China) and maintained in DMEM/F12 (Gibco, Auckland, NZ) supplemented with $10 \%$ fetal bovine serum (FBS) (Gibco, Carlsbad, CA). Prior to treatment with different concentrations of $\mathrm{E}_{2}$ or $10^{-7} \mathrm{~mol} / \mathrm{L}$ ICI 182,780 , cells were cultured at the same density in serum-free medium for $72 \mathrm{~h}$ to minimize the influence of FBS. For demethylation studies, cells were treated with $5 \mu \mathrm{M} 5$-aza-dC for $72 \mathrm{~h}$.

\section{Cell transfection}

The ER $\alpha$ expressing plasmid (exER $\alpha$ ) and its control vector $(\mathrm{EV})$, and the shRNA against $\mathrm{ER} \alpha(\operatorname{shER} \alpha)$ and its 
control vector (shNC) were all purchased from Genecreat (Shanghai). The PIWIL1 expression plasmid (exPiwil1) and its control vector (EV), and shRNA against PIWIL1 (shPiwil1) and its control vector (shNC) were all purchased from Genepharma (Shanghai). Cells were transiently transfected using Lipofectamine 2000 (Invitrogen Life Technologies; USA) according to the manufacturer's protocol.

\section{Cell proliferation assay}

Cells were plated in 96-well plates with 2000 cells/well and was divided into the different groups: control (EV /shNC, control vector), only in the presence of $E_{2}$ $\left(10^{-8} \mathrm{~mol} / \mathrm{L}\right)$, exPiwill, shPiwill, $\mathrm{E}_{2}$ plus exPiwil1 and $\mathrm{E}_{2}$ plus shPiwil1. Then, $20 \mu \mathrm{L}$ MTT was added to each well before incubation at $37^{\circ} \mathrm{C}$ for $4 \mathrm{~h}$. Absorbance values were then measured at $490 \mathrm{~nm}$ using a microplate reader (Bio-Red).

\section{Promoter-luciferase reporter assay}

A luciferase reporter assay was performed as described previously [29, 30]. PIWIL1 promoter reporter-containing plasmid (WT: wild type, MUT: mutation of the half-ERE, DEL: deletion of the half-ERE, Fig. 3a) and ER $\alpha-$ expressing plasmid were purchased from ELK Biotechnology CO., LTD (Shanghai). Ishikawa, RL95-2 and HEC-1B cells were seeded into 24-well plates at a density of $1 \times 10^{5}$ per well on the day prior to transfection. The following day, PIWIL1 promoter reporter-containing plasmid (WT, MUT and DEL) together with internal control plasmid expressing Renilla-luciferase were co-transfected using Lipofectamine 2000 (Invitrogen Life Technologies; USA). Reporter activity was measured at $48 \mathrm{~h}$ post-transfection using a Dual-Luciferase Assay System (Promega; Madison, WI, USA). Besides, cells which were stimulated with or without $17 \beta-\mathrm{E}_{2}\left(10^{-8} \mathrm{~mol} / \mathrm{L}\right)$ were also co-transfected with PIWIL1 promoter reporter-containing plasmid (WT, MUT and DEL), ER $\alpha$-expressing plasmid and internal control plasmid expressing Renilla-luciferase to examine the role of ER $\alpha$ in PIWIL1 expression.

\section{Chromatin Immunoprecipitation (ChIP) assay}

ChIP assays were performed using a ChIP assay kit (Millipore) as previously described in the Ishikawa cell line $[27,29,31]$. Samples were sonicated to shear DNA to an average fragment size of 200-1000 bp. Precipitated DNA was analyzed by qPCR with PIWIL1 promoterspecific primers Primer pair1, Primer pair2 and Primer pair3 (Fig. 4a and Additional file 2: Table S2) [29]. Enrichment was calculated using the $2^{-\Delta \mathrm{Ct}}$ formula. IgG was used as negative control.

\section{Bisulfite sequencing PCR}

According to the manufacture's instruction, genomic DNA was isolated using the DNA Extraction Mini Kit (TIANGEN Biotech, Beijing, China) and bisulfite modification was performed with the EZ DNA Methylation Gold Kit (ZYMO Research, Los Angeles, CA, USA). Primer sequences for bisulfite sequencing of the PIWIL1 fragment were 5'-GGTGTTTTGGGGGGTTAGG-3' (forward) and 5' -ACCTCCCAAAACCTCCTTC-3' (reverse), which were used to amplify a $376 \mathrm{bp}$ product. This area contains $40 \mathrm{CpG}$ sites. The PCR conditions were: denaturation at $95^{\circ} \mathrm{C}$ for $4 \mathrm{~min}, 35$ cycles at $95^{\circ} \mathrm{C}$ for $30 \mathrm{~s}, 56^{\circ} \mathrm{C}$ for 30 s, and $72{ }^{\circ} \mathrm{C}$ for $30 \mathrm{~s}$. PCR products were purified directly using the TIAN gel Midi Purification Kit (TIANGEN Biotech, Beijing, China) and ligated into the pGEM-T easy vector (Promega Corporation, Madison, WI, USA). Purified plasmid DNA containing the PIWIL1 sequence was sequenced.

\section{Statistical analysis}

All data analyses were performed using the software package SPSS v. 18.0 (SPSS Inc., Chicago, IL, USA). Data were presented as mean \pm SD and Student's t-test was used for comparison between two groups. Correlation analysis was performed with the Spearman's test. $p$ values $<0.05$ were considered statistically significant. All experiments were performed at least three times.

\section{Results}

PIWIL1 expression induced by $E_{2}$ in endometrial cancer

cells

We first utilized different concentrations of $\mathrm{E}_{2}\left(10^{-10} \sim\right.$ $10^{-8} \mathrm{~mol} / \mathrm{L}$ ) to stimulate three endometrial cancer lines and analyzed the expression of PIWIL1 at different times $(24 \mathrm{~h}, 48 \mathrm{~h}, 72 \mathrm{~h})$. We found that the expression of PIWIL1 was up-regulated by $\mathrm{E}_{2}$ treatment in a time- and dose-dependent manner in Ishikawa and RL95-2 cells (Fig. 1a and b). For HEC-1B cells, we found that estrogen regulated the expression of PIWIL1 in another timeand dose-dependent manner (Fig. 1c).

\section{Involvement of the ERa in $\mathrm{E}_{2}$-induced PIWIL1 expression} Using an ER $\alpha$ antagonist (ICI 182,780, $10^{-7} \mathrm{~mol} / \mathrm{L}$ ), we found that the increased level of PIWIL1 induced by $E_{2}$ $\left(10^{-8} \mathrm{~mol} / \mathrm{L}\right)$ was suppressed in Ishikawa and RL95-2 cells (Fig. 2a and b).

To further understand the regulatory relationship between PIWIL1 and estrogen-ER $\alpha$ signaling, Ishikawa and RL95-2 cells were transfected with ER $\alpha$ shRNA (shER $\alpha)$ and HEC-1B cells was transfected with ER $\alpha$-expressing vector $(e x E R \alpha)$. These results showed that silencing ER $\alpha$ decreased the expression of PIWIL1 and overexpression of ER $\alpha$ increased the expression of PIWIL1 (Fig. 2c). These results suggested that estrogen-ER $\alpha$ signaling can 

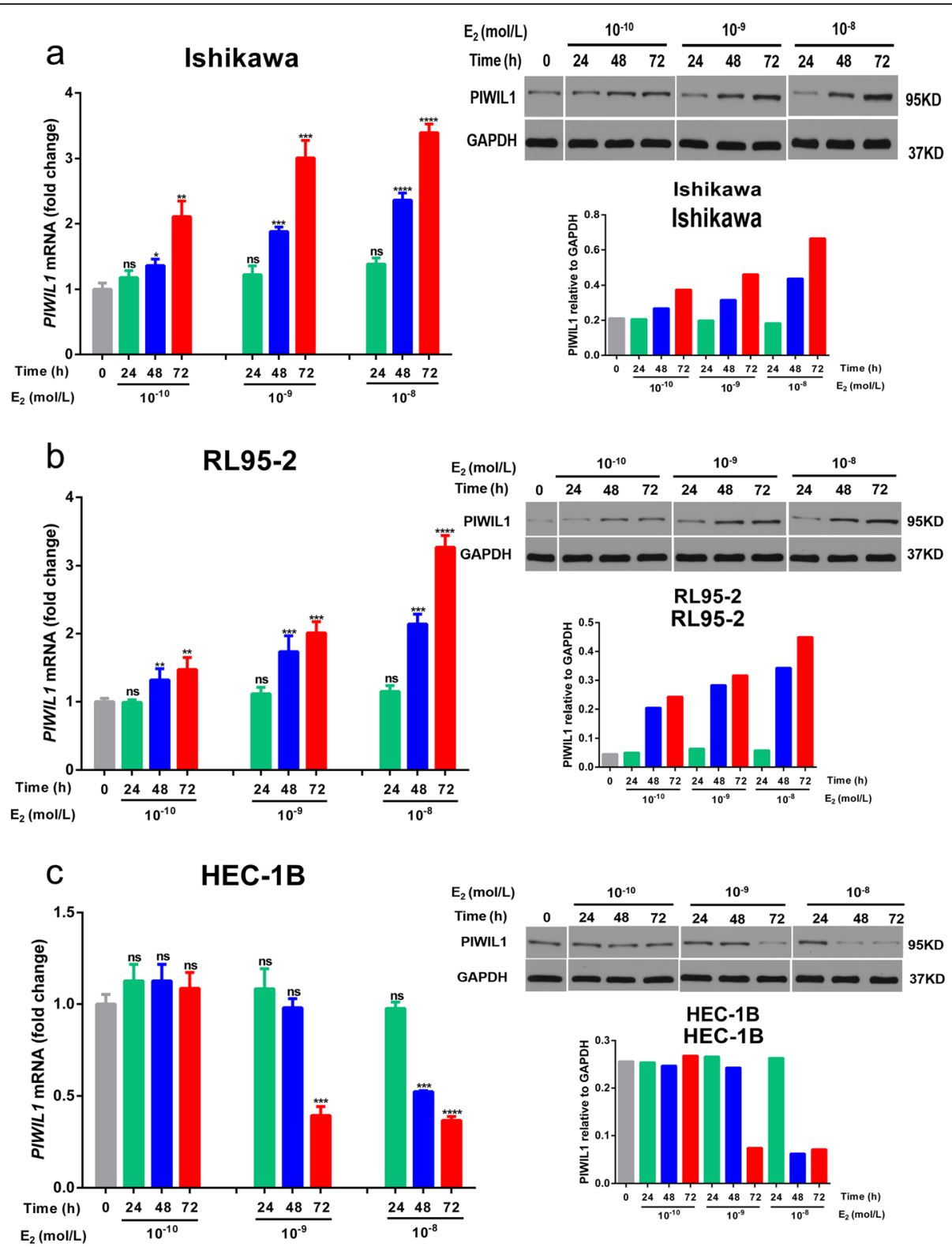

Fig. 1 Effects of estrogen on PIWIL1 expression in endometrial cancer cells. a,b,c Ishikawa, RL95-2 and HEC-1B cells were treated for treated for different times $(24 \mathrm{~h}, 48 \mathrm{~h}, 72 \mathrm{~h})$ with different concentrations of $\mathrm{E}_{2}\left(10^{-10} \sim 10^{-8} \mathrm{~mol} / \mathrm{L}\right)$. PIWIL1 mRNA and protein levels were measured by RTqPCR and western blot. Data were represented as means \pm SD for three independent experiments (RT-qPCR). ${ }^{*} p<0.05,{ }^{* *} p<0.01,{ }^{* * *} p<0.001$, ${ }^{* * * *} p<0.0001$ and ns, not significant versus control group. GAPDH was used as an internal control (western blot)

up-regulate the expression of PIWIL1 in ER $\alpha$-positive endometrial cancer cells.

\section{Effect of the half-ERE in the PIWIL1 promoter for ERa binding}

Analysis of the PIWIL1 promoter reveals a half-ERE (5'GGTCA-3') [32] at 1112 bp upstream to its translation start site, which is surrounded by GC-rich regions. To test whether this half-ERE is involved in ER $\alpha$ binding onto the PIWIL1 promoter, we constructed a PIWIL1 promoterluciferase reporter plasmid (wild type, WT) (Fig. 3a) and evaluated the effect of estrogen-ER $\alpha$ signaling on the activity of the PIWIL1 promoter in Ishikawa, RL95-2 and HEC-1B cells. In Ishikawa and RL95-2 cells, $E_{2}$ treatment significantly increased PIWIL1 promoter activities as determined by luciferase assays (Fig. 3b). Without ER $\alpha$ expression, $E_{2}$ did not induce any promoter activities in HEC-1B cells (Fig. 3c), indicating the necessity of ER $\alpha$ in the estrogen-induced PIWIL1 promoter activity. Reexpression of ER $\alpha$ increased PIWIL1 promoter activities and a combination of ER $\alpha$ expression vector and $E_{2}$ treatment dramatically increased the activity (Fig. 3c). We next 

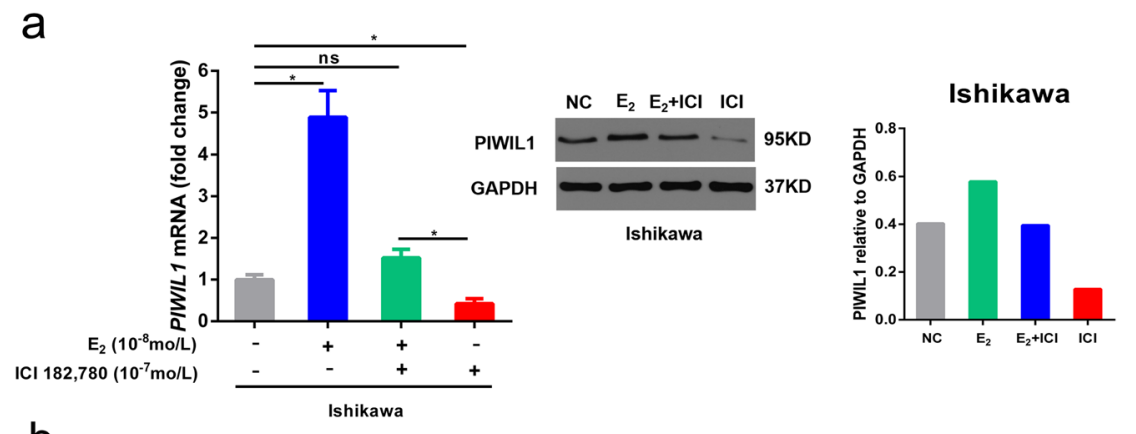

b
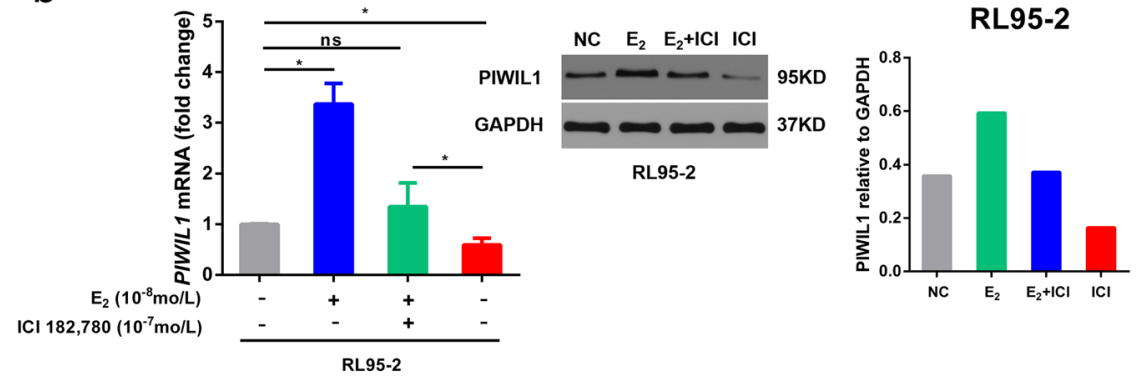

C
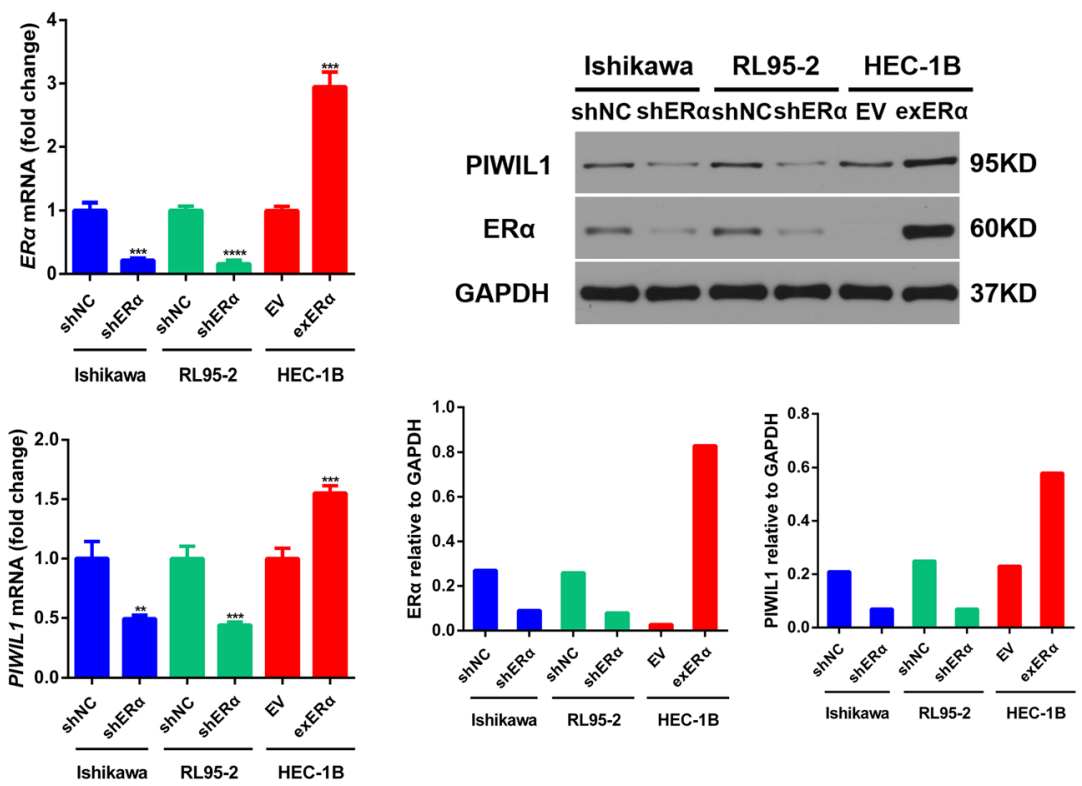

Fig. 2 Involvement of the ERa in $E_{2}$-induced PIWIL1 expression. $\mathbf{a}$ and $\mathbf{b}$ The ERa antagonist ICI 182,780 (10-7 mol/L) was used to examine ERa in $E_{2}$-induced PIWIL1 induction in Ishikawa and RL95-2 cells. c Ishikawa and RL95-2 cells were transfected with ERa shRNA (shERa) and HEC-1B was transfected with ERa expressing vector (exERa). The mRNA and protein levels of PIWIL1 and ERa were then assayed using RT-qPCR and western blot. Data were represented as means \pm SD for three independent experiments (RT-qPCR). ${ }^{*} p<0.05,{ }^{* *} p<0.01,{ }^{* * *} p<0.001,{ }^{* * *} p<0.0001$ and ns, not significant versus control group. GAPDH was used as an internal control (western blot)

constructed two additional PIWIL1 promoter-luciferase reporter plasmids (Mutation of the half-ERE, MUT [30]; Deletion of the half-ERE, DEL; Fig. 3a). We transfected MUT or DEL into Ishikawa and RL95-2 cells. $E_{2}$ treatment didn't increase the activities (Fig. 3d and e). After co-transfection with the ER $\alpha$-expression vector and MUT or DEL into HEC-1B cells, mutation or deletion of the ERE sequence of PIWIL1 abolished the promotion effect of estrogen-ER $\alpha$ signaling (Fig. $3 \mathrm{f}$ and g). These results further support the PIWIL1 expression is up-regulated by estrogen-ER $\alpha$ signaling and suggest that the half-ERE in the PIWIL1 promoter is essential for ER $\alpha$ binding.

\section{$E_{2}$-induced binding of the ERa onto the PIWIL1 promoter} Then we performed ChIP-qPCR to determine whether estrogen induces the binding of the $\mathrm{ER} \alpha$ onto the 


\section{a

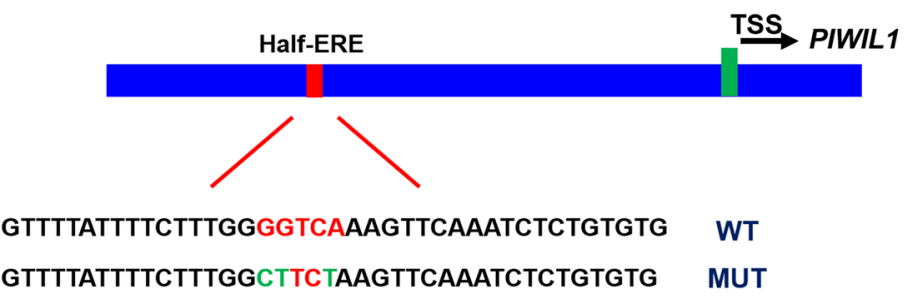

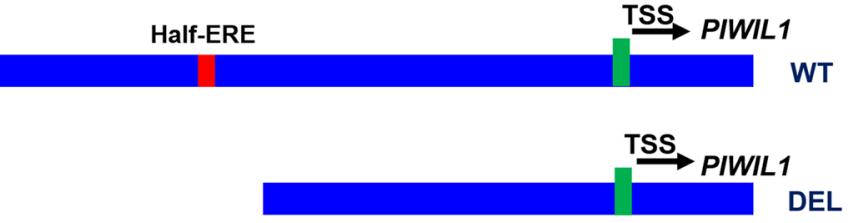

b

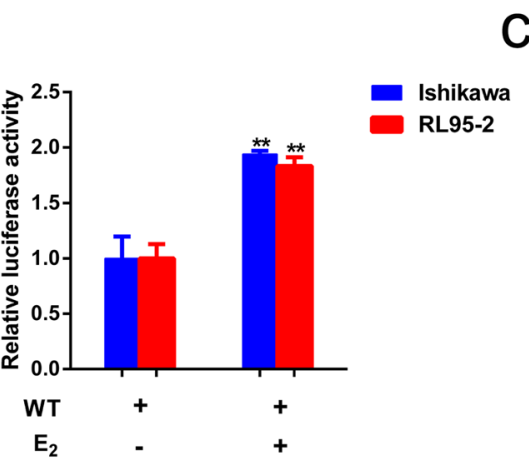

e

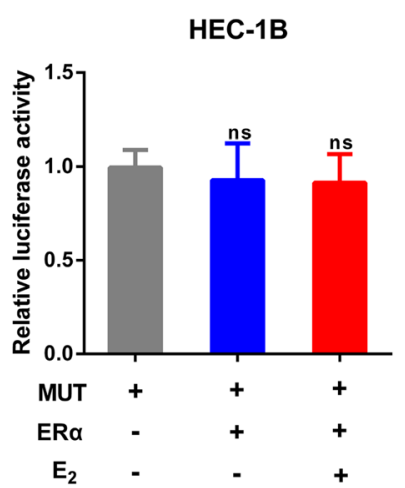

C

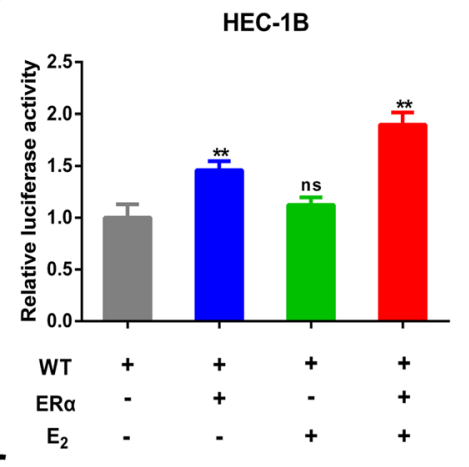

$f$

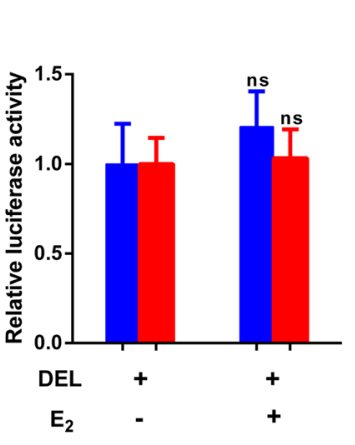

d

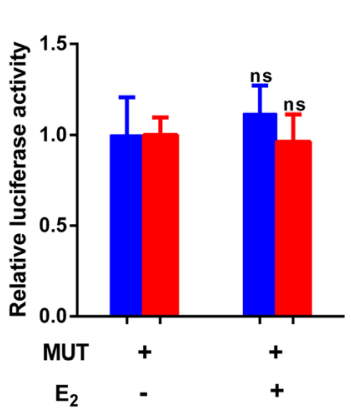

Ishikawa RL95-2

Fig. 3 Estrogen up-regulates the transcription of PIWIL1. a A schematic of three PIWIL1 promoter-luciferase reporter constructs (wild type, WT; Mutation of the half-ERE, MUT; Deletion of the half-ERE, DEL) was shown. $\mathbf{b}$ and $\mathbf{c}$ Luciferase activities of the WT reporter in endometrial cancer cell lines. $\mathbf{d}$ and $\mathbf{e}$ Luciferase activities of the WUT reporter in endometrial cancer cell lines. $\mathbf{f}$ and $\mathbf{g}$ Luciferase activities of the DEL reporter in endometrial cancer cell lines. The expression construct of ERa was co-transfected into ERa-negative cell lines. All experiments were performed at three times. ${ }^{* *} p<0.01$ and ns, not significant versus control group

PIWIL1 promoter. We designed three pairs of PCR primers used to amplify the PIWIL1 promoter DNA: Primer pair 1, Primer pair 2 and Primer pair 3 [29]. The half-ERE was in the fragment amplified by Primer pair1 (Fig. 4a). Ishikawa cells grown in regular media were lysed to prepare the chromatin DNA and then subjected to ChIP with anti-ER $\alpha$ antibody. Our study showed that the DNA amplified by Primer pair 1 was the most abundant followed by Primer pair 2. These results suggest that estrogen up-regulates the transcription of PIWIL1 by inducing the binding of the ER $\alpha$ onto the PIWIL1 promoter at the half-ERE (Fig. 4b). 


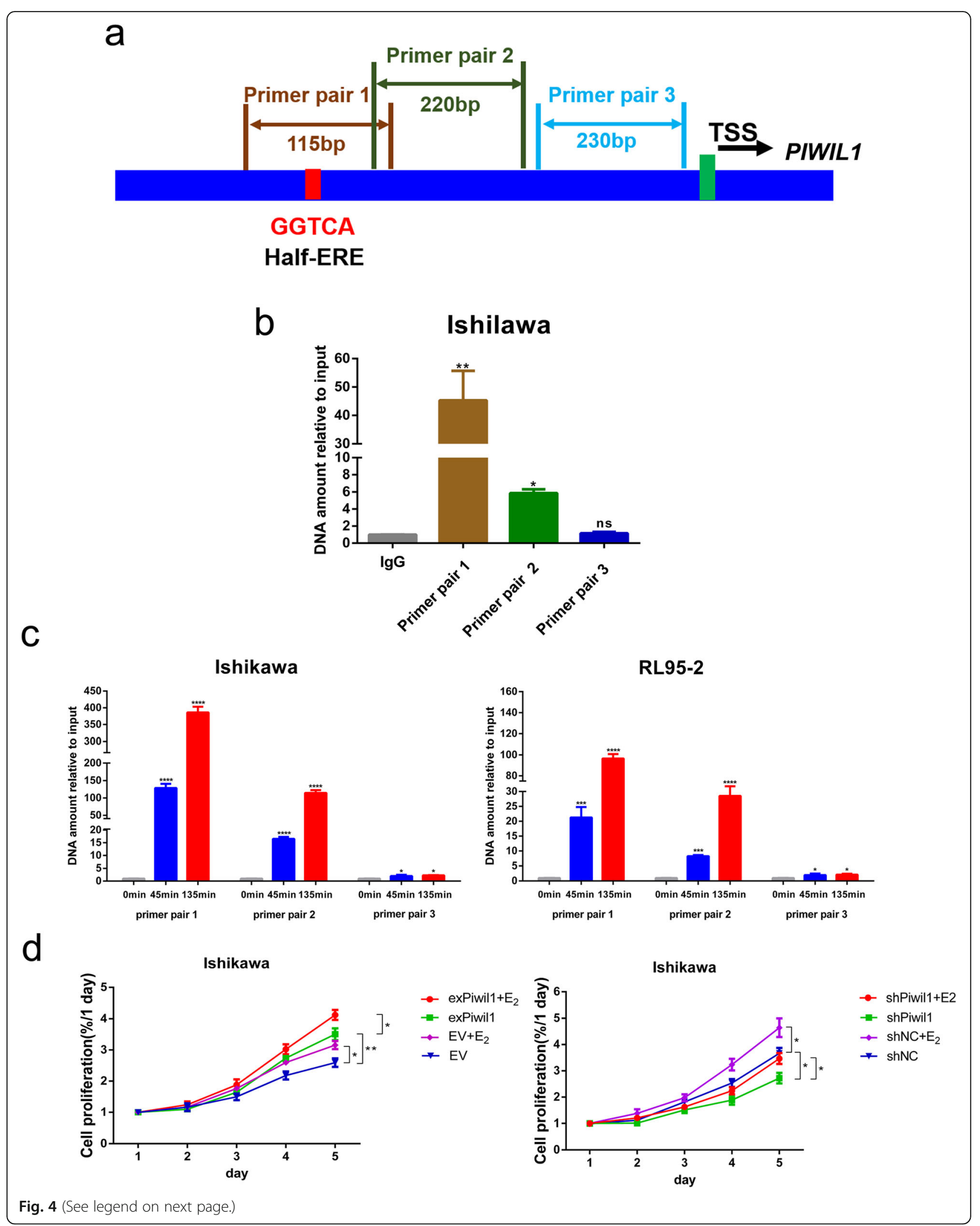


(See figure on previous page.)

Fig. $4 \mathrm{E}_{2}$-induced binding of the ERa onto the PIWIL1 promoter by estrogen. a A Schematic representation of the half-ERE in the PIWIL1 promoter and the three pairs of primers used for ChIP-qPCR was shown. TSS: transcription start sites. $\mathbf{b}$ the PIWIL1 promoter region was precipitated by the antibody against ERa in Ishikawa cells cultured in normal media. IgG served as the negative control. RT-qPCR was performed on ChIP samples. ${ }^{*} p<0.05$, ${ }^{*} p<0.01$ and ns, not significant versus control group. $\mathbf{c}$ Ishikawa cells treated with $10^{-8}$ mol/L $E_{2}$ for 0,45 , and 135 min were subjected to ChIP and the precipitated DNA was analyzed by RT-qPCR. Experimental conditions are identical to those in panel $\mathbf{b}$, except that cells were cultured in hormone-free media for $72 \mathrm{~h}$ before $\mathrm{E}_{2}$ treatment. All experiments were performed at three times. ${ }^{*} p<0.05$, ${ }^{* *} p<0.001$ and ${ }^{* * *} p<0.0001$ versus control group (cells without $E_{2}$ treatment). $\mathbf{d}$ the effects of PIWIL on $E_{2}$-induced cell growth were determined by MTT assay. ${ }^{*} p<0.05$ and ${ }^{*} p<0.01$ versus control group

ER $\alpha$ cycles onto and off promoters of its target genes in response to $E_{2}$ and its promoter occupancy peaks at 45 and $135 \mathrm{~min}$ post- $\mathrm{E}_{2}$ treatment [29]. We supposed that whether the binding of the ER $\alpha$ onto the PIWIL1 promoter fits this model. To test this possibility, we examined the binding of the ER $\alpha$ at different time points after $E_{2}$ treatment in Ishikawa and RL95-2 cells using ChIP-qPCR. ER $\alpha$ occupancy on the PIWIL1 promoter was hardly detectable without $\mathrm{E}_{2}$ treatment but was increased by $E_{2}$ treatment for both 45 and $135 \mathrm{~min}$ (Fig. 4c).

\section{Involvement of the PIWIL1 in $\mathrm{E}_{2}$-induced cell growth}

To establish the role of PIWIL1 in mediating the proliferative effect of estrogen and to investigate the possible involvement of PIWIL1 in endometrial carcinogenesis, we used the MTT assay. Ishikawa cells were transfected with the PIWIL1 expression plasmid (exPiwil1), shRNA against PIWIL1 (shPiwil1) and their control vector (EV or shNC). The transfection efficiency was demonstrated in our previous study [9]. Cell growth was monitored in these cells that received no treatment or treatment with estrogen. In the cells that transfected with EV or shNC, $\mathrm{E}_{2}$ stimulated cell growth (Fig. 4d). In the cells that transfected with exPiwil1, cell growth was observed even with no $E_{2}$ treatment. Treatment with estrogen further enhanced the cell growth (Fig. 4d). In the cells that transfected with shPiwil1, cell growth stimulation by estrogen was greatly attenuated (Fig. 4d). Collectively, these experiments strongly indicate that PIWIL1 is a key effector of the estrogen-induced cell growth in endometrial cancer.

\section{Detection of ERa and PIWIL1 in endometrial cancer tissues}

To further investigate whether PIWIL1 was regulated by estrogen-ER $\alpha$ signaling in endometrial cancer, we analyzed the expression of ER $\alpha$ and PIWIL1 in the 30 endometrial cancer samples (15 ER $\alpha$-positive endometrial cancer samples and $15 \mathrm{ER} \alpha$-negative endometrial cancer samples) used immunohistochemistry. In our study, PIWIL1 immunoreactivity was mainly observed in ER $\alpha$ positive endometrial cancer tissues (Fig. 5a). The mean scores for PIWIL1 staining were 10.32 for ER $\alpha$-positive endometrial cancer samples and 1.82 for ER $\alpha$-negative endometrial cancer samples (Fig. 5b). Then the mRNA expression levels of $E R \alpha$ and PIWIL1 were measured by $\mathrm{RT}-\mathrm{qPCR}$ in 30 endometrial cancer samples. The ER $\alpha$ had a positive correlation with PIWIL1 in endometrial cancer tissue $\left(r=0.8,{ }^{* * * *} p<0.0001\right.$; Fig. $\left.5 c\right)$. Taken together, these results further suggest there is a relationship between PIWIL1 and estrogen-ER $\alpha$ signaling in endometrial cancer. We examined the RNA-seq data from the TCGA and found that there was also a positive correlation between PIWIL1 and ER $\alpha$ expression in cervical cancer, kidney cancer, prostate adenocarcinoma, testicular germ cell tumors and cutaneous melanoma (data not shown).

\section{PIWIL1 promoter hypomethylation}

To understand why PIWIL1 is activated in endometrial cancer, we examined the methylation status of PIWIL1 promoter in Ishikawa, RL95-2 and HCE-1B cells. We performed direct sequencing analysis of a 376-bp fragment including $40 \mathrm{CpG}$ dinucleotides in the PIWIL1 promoter at $\sim 225 \mathrm{bp}$ upstream to its transcription start site and at $\sim 511$ bp downstream to the half-ERE binding site. Differential methylation was observed in $40 \mathrm{CpG}$ dinucleotides of the promoter in the three endometrial cancer cells (Fig. 6a). We found that the percentage of methylated CpG dinucleotides in Ishikawa, RL95-2 and HEC-1B was 45.83, 40.00 and $86.67 \%$, respectively (Fig. 6b), suggesting that the reactivation of PIWIL1 expression in endometrial cancer is associated with hypomethylation of the PIWIL1 promoter. Moreover, we assessed the expression of PIWIL1 mRNA and protein after treatment with 5 -aza-dC in HEC-1B cells. After treatment with 5 -aza-dC, we found that HEC-1B cells showed reactivation of both PIWIL1 mRNA and protein expression (Fig. 6c).

\section{Discussion}

PIWIL1 is a member of the PIWI proteins, which are involved in stem cell self-renewal, division, spermatogenesis, RNA silencing, and translational regulation [33]. Cancer cells share several characteristics with stem cells, such as rapid proliferation and virtually infinite selfrenewal. Therefore, it is not surprising that germline 


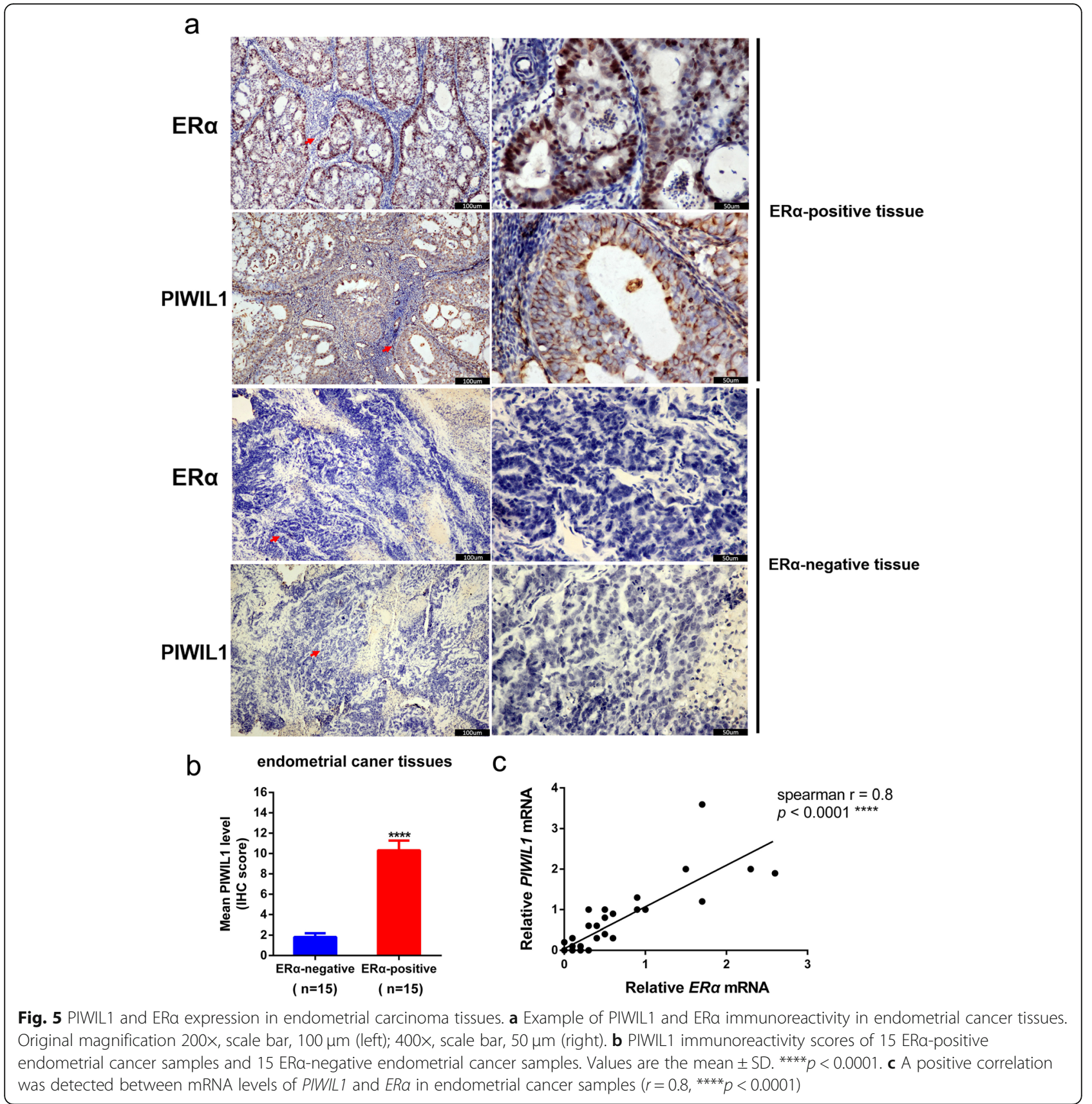

factors would also be involved in carcinogenesis [34]. Our previous study revealed PIWIL1 as an oncogene in endometrial cancer $[9,35]$. In the present study, for the first time, we wanted to elicit the potentially molecular mechanism involved in regulating the expression of PIWIL1 in endometrial cancer.

Several studies found that estrogen could regulate the expression of the PIWI family [20, 21]. In our previous study, we found that the expression of PIWIL1 was higher in ER $\alpha$-positive cell lines (Ishikawa and RL95-2). Our continued examination in this study indicates that estrogen could up-regulate the expression of PIWIL1 in ER $\alpha$-positive endometrial cancer cells (Fig. 1). However, our results also found that estrogen showed the function of down-regulation of PIWIL1 expression in ER $\alpha$-negative endometrial cancer cell line. This finding raises the possibility that there may be another mechanism in ER $\alpha$ negative cell lines which warrants further investigation.

Estrogen exerts its biological activities by binding ERs, $E R \alpha$ and ER $\beta$, which mediate cellular responses to hormone exposure. The adult uterus is found, in general, to have very low expression of ER $\beta$ compared with ER $\alpha$ 
a

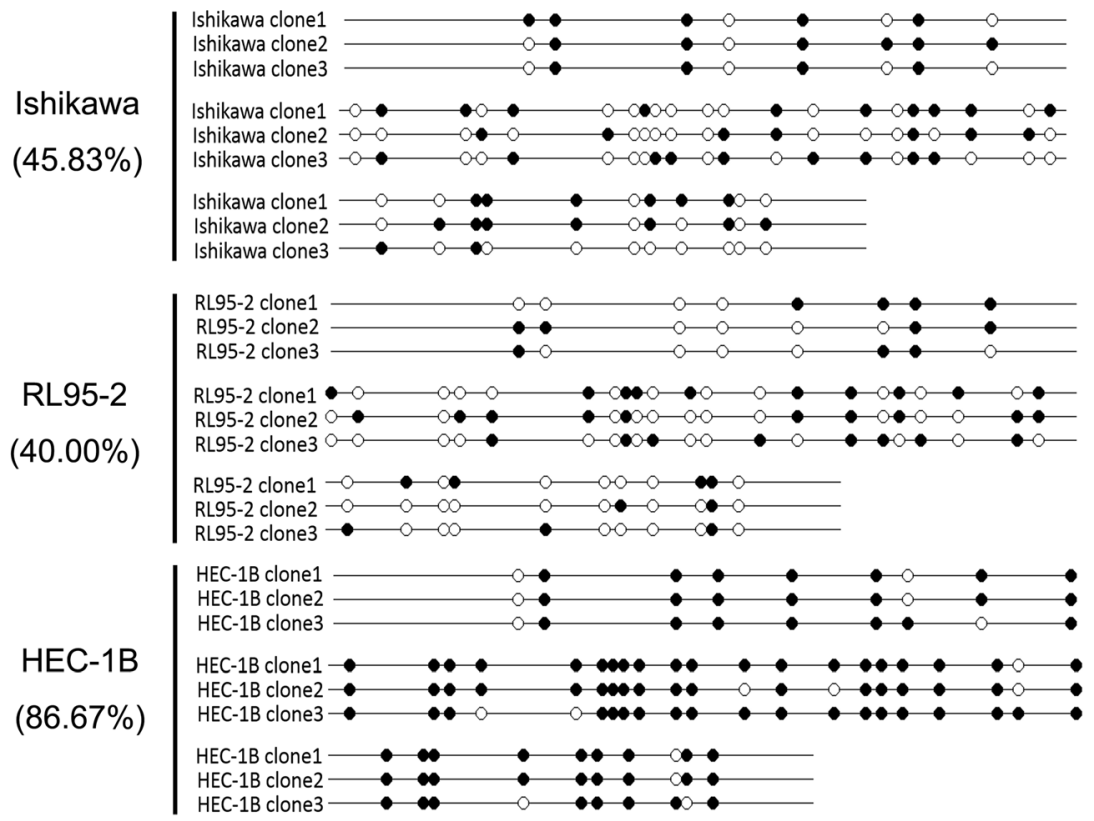

b

C HEC-1B

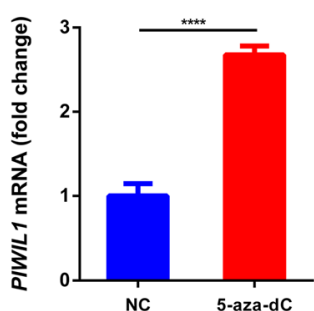

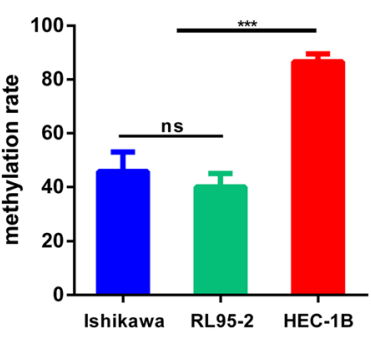

HEC-1B

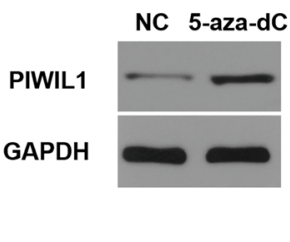

$37 K D$

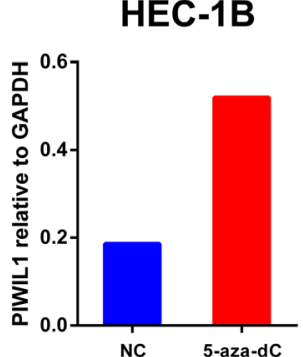

Fig. 6 Cancer-linked hypomethylation of the PIWIL1 promoter. a Results of bisulfite DNA sequencing of the PIWIL1 upstream regulatory region in Ishikawa, RL95-2 and HEC-1B cells. Black dots symbolize methylated CpGs and white dots symbolize unmethylated CpGs. b The percentage of methylated CpG dinucleotides in Ishikawa, RL95-2 and HEC-1B cells. ${ }^{* * *} p<0.001$ and ns, not significant. c RT-qPCR and western blot showed changes in PIWIL1 mRNA and protein expression in HEC-1B cells after treatment with 5-aza-dC. Data were represented as means \pm SD for three independent experiments (RT-qPCR). ${ }^{* * *} p<0.0001$ versus control group. GAPDH was used as an internal control (western blot)

[36]. Moreover, it is well accepted that estrogenic effect occurs predominantly through ER $\alpha$ in endometrial cancer. In this study, we further confirmed that estrogen could up-regulate the expression of PIWIL1 through $E R \alpha$, which was based on multiple lines of evidence, including up-regulation of PIWIL1 by overexpression of ER $\alpha$ expression and down-regulation of PIWIL1 by the knockdown of ER $\alpha$ expression or using an ER $\alpha$ antagonist (Fig. 2). Therefore, it is assumed that estrogen could up-regulate the expression of PIWIL1 through ER $\alpha$.

Estrogen-mediated signaling pathways can be divided into genomic signaling pathways and non-genomic signaling pathways [37]. ER $\alpha$ regulates genes through directly binding to DNA at estrogen response elements (EREs) or through protein-protein interactions with 
other direct DNA binding transcription factors, such as Sp1 and Ap1 [38-40]. Genome-wide analysis of ER $\alpha$ binding has uncovered thousands of loci bound by ER $\alpha$ after $E_{2}$ induction and the most common motif identified at these loci is the full palindromic ERE (5'-GGTC AnnnTGACC-3') [32]. However, the majority of bound sites of ER $\alpha$ do not have full palindromic sequence and usually harbor only half EREs [41, 42]. Direct promoter binding usually involves an ERE with a typical consensus sequence or a half-ERE positioned next to GC-rich regions in their promoters [29]. Stender et al. performed an unbiased search for DNA motifs enriched in the identified ER binding sites and found five most enriched DNA motifs in the WT ER binding sites including the half-ERE (GGTCA) [43]. The PIWIL1 promoter does not have classical palindromic ERE. Instead, it contains a

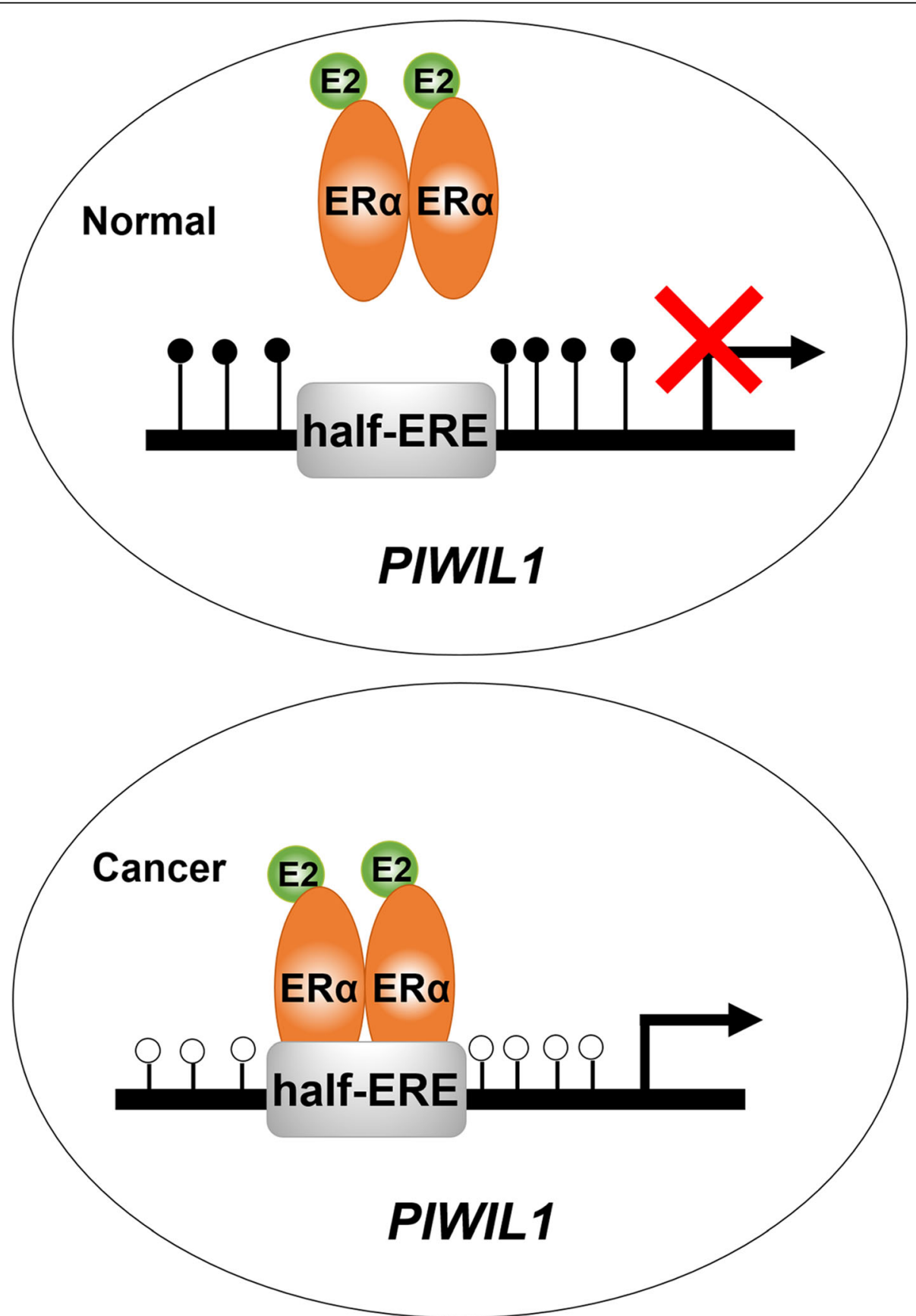

Fig. 7 Proposed model of the cooperation between $E_{2}$-ERa signaling and DNA hypomethylation for the regulation of stem cell protein PIWIL1. upper: In normal cells, hypermethylation of PIWIL1 promoter prevents the binding of $E_{2}$-ERa complex to PIWIL1 promoter. Lower: In endometrial cancer cells, increased PIWIL1 expression regulated by $E_{2}-E R a$ signaling is due to the cancer-linked hypomethylation of the PIWIL1 promoter 
half-ERE (GGTCA) which is surrounded by GC-rich regions in the PIWIL1 promoter, located $\sim 1112 \mathrm{bp}$ upstream to the translation start site. In our study, we found that this half-ERE was essential for the binding of the ER $\alpha$ onto the PIWIL1 promoter, as revealed by Luciferase assay and ChIP-qPCR (Figs. 3 and 4a-c). However, we can't entirely exclude the possibility that activation of the PIWIL1 by estrogen requires binding of some yet unidentified ER $\alpha$-associated proteins to ER $\alpha$ at the PIWIL1 promoter. Therefore, further studies are required to identify the detailed mechanism involved in regulation of ER $\alpha$ on PIWIL1.

Endometrioid carcinoma (Type I carcinomas) is the most common type of endometrial carcinoma. This process is commonly associated with unopposed estrogen stimulation [1]. Our observation indicated that PIWIL1 had a role in $\mathrm{E}_{2}$-stimulated cancer cells proliferation (Fig. 4d). In our study, IHC analysis showed that the level of PIWIL1 expression was significantly correlated with that of ER $\alpha$ expression. Furthermore, RTqPCR analysis and bioinformatics analysis were performed to confirm our result (Fig. 5). This correlation further suggests that PIWIL1 may be a downstream target of ER $\alpha$ and may be involved in $\mathrm{E}_{2}$-stimulated endometrial carcinogenesis.

Aberrant DNA methylation have been shown to be an early event in carcinogenesis in many cancers, including endometrial cancer [44, 45]. Promoters with a high density of CpGs are defined as CG-rich areas and are predominantly subject to DNA methylation. The PIWIL1 has $5^{\prime}$ end CpG islands surrounding the corresponding transcription start sites. Gain of $5^{\prime}$ end promoter CpG island methylation for the PIWIL1 is in association with their transcriptional silencing [23]. Promoter DNA hypomethylation of PIWIL1 could also contribute to its aberrant expression $[24,25]$. In our previous study, we found that PIWIL1 was silenced in normal endometrium and reactivated in endometrial cancer [9]. In this study, we further confirm that the expression of PIWIL1 in different endometrial cancer cell lines is associated with methylation status of the PIWIL1 promoter (Fig. 6), indicating that the reactivation of PIWIL1 in endometrial cancer may be associated with cancer-linked hypomethylation of the PIWIL1 promoter. Previous studies suggest that ER $\alpha$-targeted gene expression is epigenetically regulated by ER $\alpha$ cooperating with co-activators in a classical and epigenetic manner [46]. Therefore, further studies are required to identify the detailed epigenetic mechanism involved in regulation of ER $\alpha$ on PIWIL1.

\section{Conclusions}

In summary, the study presented here demonstrates a novel molecular mechanism by which estrogen-ER $\alpha$ signaling and DNA hypomethylation co-regulate PIWIL1 expression in endometrial cancer (Fig. 7). These findings provide novel insights into the hormonal regulation in endometrial cancer and may offer novel therapeutic and preventative strategies for endometrial cancer and other hormonally-driven cancers in the future.

\section{Supplementary information}

Supplementary information accompanies this paper at https://doi.org/10. 1186/s12964-020-00563-4.

Additional file 1: Table S1. List of primers used for RT-qPCR. Additional file 2: Table S2. PIWIL1 promoter-specific primers.

\section{Abbreviations}

ER: Estrogen receptor; ChIP: Chromatin immunoprecipitation; RTqPCR: Quantitative reverse transcription-PCR; ERE: Estrogen response element; BSP: Bisulfite sequencing PCR; FIGO: Federation International of Gynecology and Obstetrics; 5-aza-dC: 5-aza-deoxycytidine; MTT: 3-(4,5dimethylthiazol-2-yl)-2,5-diphenyltetrazolium; exERa: ERa expressing plasmid; shERa: ShRNA against ERa; exPiwil1: PIWIL1 expression plasmid; shPiwil1: ShRNA against PIWIL1; EV/shNC: Control vector; WT: Wild type; MUT: Mutation of the half-ERE; DEL: Deletion of the half-ERE

\section{Acknowledgements}

Not applicable.

\section{Authors' contributions}

ZC, XYH and XPW conceived and designed the experiments. ZC, HJY, QL and MJZ, YYY performed the experiments. ZC and HJY analyzed the data. ZC wrote the manuscript. All authors read and approved the final manuscript.

\section{Funding}

This project is supported by the National Natural Science Foundation of China (No. 81702546, 81701402)

\section{Availability of data and materials}

All data generated or analyzed during this study are included in this published article.

\section{Ethics approval and consent to participate}

Informed consent was obtained from all participants, and this study was approved by the Human Investigation Ethics Committee of the authors' affiliated institution.

Consent for publication

We all consent for publication.

\section{Competing interests}

The authors declare that they have no competing interests.

\section{Author details}

${ }^{1}$ Department of Obstetrics and Gynecology, International Peace Maternity and Child Health Hospital, School of Medicine, Shanghai Jiao Tong University, No.910, Hengshan Road, Shanghai 200030, China. ${ }^{2}$ Shanghai Municipal Key Clinical Specialty, Shanghai, China. ${ }^{3}$ Shanghai Key Laboratory of Embryo Original Diseases, Shanghai, China. ${ }^{4}$ Department of Obstetrics and Gynecology, Shanghai First Maternity and Infant Hospital, Tong Ji University School of Medicine, No. 536, Changle Road, Shanghai 200080, China.

Received: 21 January 2020 Accepted: 23 March 2020

Published online: 05 June 2020

\section{References}

1. Di Cristofano A, Ellenson LH. Endometrial carcinoma. Annu Rev Pathol. 2007; 2:57-85.

2. Morice P, Leary A, Creutzberg C, Abu-Rustum N, Darai E. Endometrial cancer Lancet. 2016;387:1094-108. 
3. Zhou C, Steplowski TA, Dickens HK, Malloy KM, Gehrig PA, Boggess JF, BaeJump VL. Estrogen induction of telomerase activity through regulation of the mitogen-activated protein kinase (MAPK) dependent pathway in human endometrial cancer cells. PLoS ONE. 2013;8:e55730.

4. Zhang Z, Zhou D, Lai Y, Liu Y, Tao X, Wang Q, Zhao G, Gu H, Liao H, Zhu Y, et al. Estrogen induces endometrial cancer cell proliferation and invasion by regulating the fat mass and obesity-associated gene via PI3K/AKT and MAPK signaling pathways. Cancer Lett. 2012;319:89-97.

5. Wu H, Chen Y, Liang J, Shi B, Wu G, Zhang Y, Wang D, Li R, Yi X, Zhang H, et al. Hypomethylation-linked activation of PAX2 mediates tamoxifenstimulated endometrial carcinogenesis. Nature. 2005;438:981-7.

6. Tian W, Teng F, Zhao J, Gao J, Gao C, Sun D, Liu G, Zhang Y, Yu S, Zhang W, et al. Estrogen and insulin synergistically promote type 1 endometrial cancer progression. Cancer Biol Ther. 2017;18:1000-10.

7. Cox DN, Chao A, Baker J, Chang L, Qiao D, Lin H. A novel class of evolutionarily conserved genes defined by piwi are essential for stem cell self-renewal. Genes Dev. 1998;12:3715-27.

8. Li S, Meng L, Zhu C, Wu L, Bai X, Wei J, Lu Y, Zhou J, Ma D. The universal overexpression of a cancer testis antigen hiwi is associated with cancer angiogenesis. Oncol Rep. 2010;23:1063-8.

9. Chen Z, Che Q, He X, Wang F, Wang H, Zhu M, Sun J, Wan X. Stem cell protein Piwil1 endowed endometrial cancer cells with stem-like properties via inducing epithelial-mesenchymal transition. BMC Cancer. 2015;15:811.

10. Liu X, Sun Y, Guo J, Ma H, Li J, Dong B, Jin G, Zhang J, Wu J, Meng L, Shou C. Expression of hiwi gene in human gastric cancer was associated with proliferation of cancer cells. Int J Cancer. 2006;118:1922-9.

11. Taubert H, Greither T, Kaushal D, Wurl P, Bache M, Bartel F, Kehlen A Lautenschlager C, Harris L, Kraemer K, et al. Expression of the stem cell selfrenewal gene Hiwi and risk of tumour-related death in patients with softtissue sarcoma. Oncogene. 2007;26:1098-100.

12. Grochola LF, Greither T, Taubert H, Moller P, Knippschild U, Udelnow A, Henne-Bruns D, Wurl P. The stem cell-associated Hiwi gene in human adenocarcinoma of the pancreas: expression and risk of tumour-related death. Br J Cancer. 2008:99:1083-8.

13. Liang D, Fang Z, Dong M, Liang C, Xing C, Zhao J, Yang Y. Effect of RNA interference-related HiWi gene expression on the proliferation and apoptosis of lung cancer stem cells. Oncol Lett. 2012;4:146-50.

14. Zhao YM, Zhou JM, Wang LR, He HW, Wang XL, Tao ZH, Sun HC, Wu WZ, Fan J, Tang ZY, Wang L. HIWI is associated with prognosis in patients with hepatocellular carcinoma after curative resection. Cancer. 2012;118:2708-17.

15. Grivna ST, Pyhtila B, Lin H. MIWI associates with translational machinery and PIWI-interacting RNAs (piRNAs) in regulating spermatogenesis. Proc Natl Acad Sci USA. 2006;103:13415-13,420.

16. Xiang DF, Zhu JQ, Hou CC, Yang WX. Identification and expression pattern analysis of Piwi genes during the spermiogenesis of Portunus trituberculatus. Gene. 2014;534:240-8.

17. Bak CW, Yoon TK, Choi Y. Functions of PIWI proteins in spermatogenesis. Clin Exp Reprod Med. 2011;38:61-7.

18. Kowalczykiewicz D, Pawlak P, Lechniak D, Wrzesinski J. Altered expression of porcine Piwi genes and piRNA during development. PLoS One. 2012;7: e43816.

19. Ma X, Wang S, Do T, Song X, Inaba M, Nishimoto Y, Liu L-P, Gao Y, Mao Y. Piwi is required in multiple cell types to control germline stem cell lineage development in the drosophila ovary. PLos one. 2014;9:e90267.

20. Pan Y, Hu M, Liang H, Wang JJ, Tang LJ. The expression of the PIWI family members miwi and mili in mice testis is negatively affected by estrogen. Cell Tissue Res. 2012;350:177-81.

21. Zhang D, Duarte-Guterman P, Langlois VS, Trudeau VL. Temporal expression and steroidal regulation of piRNA pathway genes (mael, piwi, vasa) during Silurana (Xenopus) tropicalis embryogenesis and early larval development. Comp Biochem Physiol C Toxicol Pharmacol. 2010;152:202-6.

22. Liang $G$, Weisenberger DJ. DNA methylation aberrancies as a guide for surveillance and treatment of human cancers. Epigenetics. 2017;12:416-32.

23. Ferreira HJ, Heyn H, Garcia del Muro X, Vidal A, Larriba S, Muñoz C, Villanueva A, Esteller M. Epigenetic loss of the PIWI/piRNA machinery in human testicular tumorigenesis. Epigenetics. 2014;9(1):113-8.

24. Xie K, Zhang K, Kong J, Wang C, Gu Y, Liang C, Jiang T, Qin N, Liu J, Guo X, et al. Cancer-testis gene PIWIL1 promotes cell proliferation, migration, and invasion in lung adenocarcinoma. Cancer Med. 2018;7:157-66.

25. Navarro A, Tejero R, Vinolas N, Cordeiro A, Marrades RM, Fuster D, Caritg O, Moises J, Munoz C, Molins L, et al. The significance of PIWI family expression in human lung embryogenesis and non-small cell lung cancer. Oncotarget. 2015:6:31544-31,556

26. Creasman W. Revised FIGO staging for carcinoma of the endometrium. Int J Gynaecol Obstet. 2009;105:109.

27. Wei Bao H-HW, Tian F-J, He X-Y, Qiu M-T, Wang J-Y, Zhang H-J, Wang L-H, Wan X-P. A TrkB-STAT3-miR-204-5p regulatory circuitry controls proliferation and invasion of endometrial carcinoma cells. Mol Cancer. 2013; 12:155.

28. Che Q, Liu BY, Liao Y, Zhang HJ, Yang TT, He YY, Xia YH, Lu W, He XY, Chen $Z$, et al. Activation of a positive feedback loop involving IL-6 and aromatase promotes intratumoral 17beta-estradiol biosynthesis in endometrial carcinoma microenvironment. Int J Cancer. 2014;135:282-94.

29. Dong XY, Guo P, Sun X, Li Q, Dong JT. Estrogen up-regulates ATBF1 transcription but causes its protein degradation in estrogen receptor-alphapositive breast cancer cells. J Biol Chem. 2011;286:13879-13,890.

30. Tora L, Gaub M-P, Mader S, Dierich A, Bellard M, Chambon P. Cell-specific activity of a GGTCA half-palindromic oestrogen-responsive element in the chicken ovalbumin gene promoter. EMBO J. 1988;7:3771-8.

31. Tingting Yang HZ, Qiu H, Li B, Wang J, Du G, Ren C, Wan X. EFEMP1 is repressed by estrogen and inhibits the epithelialmesenchymal transition via Wnt/B-catenin signaling in endometrial carcinoma. Oncotarget. 2016;7: $25712-25,725$

32. Lin CY, Vega VB, Thomsen JS, Zhang T, Kong SL, Xie M, Chiu KP, Lipovich L, Barnett DH, Stossi F, et al. Whole-genome cartography of estrogen receptor alpha binding sites. PLoS Genet. 2007;3:e87.

33. Seto AG, Kingston RE, Lau NC. The coming of age for Piwi proteins. Mol Cell. 2007;26:603-9.

34. Suzuki R, Honda S, Kirino Y. PIWI Expression and Function in Cancer. Front Genet. 2012:3:204

35. Chen Z, Che Q, Jiang FZ, Wang HH, Wang FY, Liao Y, Wan XP. Piwil1 causes epigenetic alteration of PTEN gene via upregulation of DNA methyltransferase in type I endometrial cancer. Biochem Biophys Res Commun. 2015:463:876-80.

36. Weihua ZSS, Mäkinen S, Cheng G, Jensen EV, Warner M, Gustafsson JA. Estrogen receptor (ER) beta, a modulator of ERalpha in the uterus. Proc Natl Acad Sci U S A. 2000;97:5936-41.

37. Fuentes N, Silveyra P. Estrogen receptor signaling mechanisms. Adv Protein Chem Struct Biol. 2019;116:135-70.

38. Wang C, Mayer JA, Mazumdar A, Fertuck K, Kim H, Brown M, Brown PH. Estrogen induces c-myc gene expression via an upstream enhancer activated by the estrogen receptor and the AP-1 transcription factor. Mol Endocrinol. 2011:25:1527-38.

39. Petz LN, Nardulli AM. Sp1 binding sites and an estrogen response element half-site are involved in regulation of the human progesterone receptor a promoter. Mol Endocrinol. 2000;14:972-85.

40. Hewitt SC, Winuthayanon W, Korach KS. What's new in estrogen receptor action in the female reproductive tract. J Mol Endocrinol. 2016;56:R55-71.

41. Joseph R, Orlov YL, Huss M, Sun W, Kong SL, Ukil L, Pan YF, Li G, Lim M, Thomsen JS, et al. Integrative model of genomic factors for determining binding site selection by estrogen receptor-alpha. Mol Syst Biol. 2010;6:456.

42. Charn TH, Liu ET, Chang EC, Lee YK, Katzenellenbogen JA, Katzenellenbogen BS. Genome-wide dynamics of chromatin binding of estrogen receptors alpha and beta: mutual restriction and competitive site selection. Mol Endocrinol. 2010;24:47-59.

43. Stender JD, Kim K, Charn TH, Komm B, Chang KC, Kraus WL, Benner C, Glass CK, Katzenellenbogen BS. Genome-wide analysis of estrogen receptor alpha DNA binding and tethering mechanisms identifies Runx1 as a novel tethering factor in receptor-mediated transcriptional activation. Mol Cell Biol. 2010;30:3943-55.

44. Wentzensen N, Bakkum-Gamez JN, Killian JK, Sampson J, Guido R, Glass A, Adams L, Luhn P, Brinton LA, Rush B, et al. Discovery and validation of methylation markers for endometrial cancer. Int J Cancer. 2014;135:1860-8.

45. Trimarchi MP, Yan P, Groden J, Bundschuh R, Goodfellow PJ. Identification of endometrial cancer methylation features using combined methylation analysis methods. PLoS One. 2017;12:e0173242.

46. Hervouet E, Cartron PF, Jouvenot M, Delage-Mourroux R. Epigenetic regulation of estrogen signaling in breast cancer. Epigenetics. 2013;8:237-45.

\section{Publisher's Note}

Springer Nature remains neutral with regard to jurisdictional claims in published maps and institutional affiliations. 